\title{
The pioneers of development economics, great economists on development ${ }^{1}$
}

\author{
Carlos Aguiar de Medeiros ${ }^{2}$
}

A economia do desenvolvimento tem uma longa história. Nos anos mais recentes, os economistas neoclássicos que se mantiveram sempre distantes e críticos da disciplina abraçaram-na entusiasticamente através das teorias do crescimento endógeno e da nova economia institucionalista. Essas teorias formaram um novo corpo doutrinário que constitui hoje a visão de fundo dos documentos do Banco Mundial e das políticas de desenvolvimento sugeridas para as economias em desenvolvimento.

$\mathrm{Na}$ contramão dessa corrente de pensamento, o livro The pioneers of development economics, great economists on development (2005), organizado por K. S. Jomo (doravante Pioneers), constitui uma excelente recuperação de alguns autores clássicos e dos dilemas centrais da economia do desenvolvimento.

Jomo, em sua introdução ao Pionneers, ${ }^{3}$ observa, numa análise semelhante à de Chakravarty (1997), que, embora a "economia do desenvolvimento" seja uma disciplina recente, a "teorização do desenvolvimento na economia" constitui, essencialmente, o objeto do pensamento iniciado com William Petty. A superação dessa distinção é essencial em face da ofensiva neoclássica. Na medida em que esta se apropria das idéias desenvolvidas por aqueles autores descontextualizando-as e submetendo-as aos seus paradigmas, reivindica um status de teoria geral, uma síntese mais precisa daquelas "boas idéias não formalizadas". 4 A busca de uma integração das teorias desenvolvidas pelos autores consagrados da "economia do desenvolvimento" com as teorias dos economistas clássicos, keynesianos e institucionalistas é extraordinariamente oportuna.

Prabhat Patnaik, no seu capítulo "Why development economics?", indaga sobre a origem da persistente separação entre "teoria econômica" e a "economia do desenvolvimento". Uma possível resposta seria a suposição (não apenas feita por neoclássicos, mas também por Marx) de que como os países em desenvolvimento seguem com atraso as mesmas trajetórias dos países avançados, é lógico e racional que a teoria deva assumir em sua análise do funcionamento da economia as instituições prevalecentes nos países desenvolvidos, ficando para o campo da "economia do desenvolvimento" as referências concretas aos problemas econômicos e institucionais em áreas atrasadas.

$\mathrm{O}$ autor sustenta que essa forma de pensar tem um problema: ela considera as economias desenvolvidas de forma isolada. Ele ilustra esse argumento com três exemplos: a teoria neoclássica do crescimento, a teoria da taxa de desemprego natural e a teoria do

(1) Editado por Jomo Kwame Sundaram (Jomo K. S.).London: Zed Books, 2005.

(2) Professor do Instituto de Economia da Universidade Federal do Rio de Janeiro (UFRJ) e visitante da Universidade de Cambridge. O autor agradece o apoio financeiro da Coordenação de Aperfeiçoamento de Pessoal de Nível Superior (Capes). Para não sobrecarregar esta resenha, foram incluídas apenas as referências bibliográficas dos textos utilizados em apoio aos meus comentários e não as dos textos que constituem o material explorado pelos autores desta coleção.

(3) Lançado em conjunto com dois outros livros editados pelo autor: The origins of development economics, em co-edição com Erik S. Reinert, em 2005, e The new development economics, com Ben Fine, em 2006, ambos pela Zed Books. Ver Chakravarty (1997).

(4) Numa direção semelhante, esse aspecto foi desenvolvido em Medeiros e Serrano (2004).

Economia e Sociedade, Campinas, v. 16, n. 1 (29), p. 125-130, abr. 2007. 
comércio internacional. Na teoria neoclássica convencional do crescimento econômico, o trabalho é considerado um "fator escasso", isto é, não pode ser produzido ou adquirido em quantidades adequadas à taxa de salário corrente. A crítica principal de Patnaik é que essa proposição desconsidera essencialmente o exército de reserva constituído pela população localizada fora das metrópoles. A imensa escala dos deslocamentos demográficos, tanto no século XIX quanto no capitalismo do pós-guerra, eliminou qualquer hipótese de restrição da taxa de acumulação por escassez de trabalho.

Esse mesmo argumento é utilizado em sua crítica à teoria neoclássica da taxa natural de desemprego (NRU) e à taxa de desemprego não aceleradora da inflação (NAIRU). Existem níveis particulares de NAIRU associados a diferentes termos de troca, mas como os salários no Terceiro Mundo são compressíveis sem aceleração da inflação, os termos de troca podem tornar-se negativos aos produtores do Terceiro Mundo independentemente do nível de emprego nos países industrializados.

Em relação à teoria do comércio internacional, Prabhat Patnaik segue o argumento desenvolvido exaustivamente por Utsa Patnaik em seu capítulo "Ricardo's fallacy: mutual benefit from trade based on comparative costs and specialization?". A proposição implícita na tese de que "livre comércio é melhor do que nenhum comércio" baseia-se na suposição de que a cesta de bens disponíveis pós-comércio é maior do que na situação pré-comércio. Mas isso só é possível, argumentam os dois autores, se, no caso simples de dois países e dois bens (o clássico exemplo de Ricardo), ambos pudessem produzir os mesmos dois bens. Essa irrealista hipótese da auto-suficiência e de uma sempre possível (e desejada) substituição - os países industrializados não podiam e não podem produzir produtos primários - está presente quer nas versões ricardianas, quer em Hecksher-Ohlin.

Com esses três exemplos, Patnaik argumenta que a dicotomia entre "teoria econômica" e "desenvolvimento econômico" deve ser rejeitada. Os países em desenvolvimento não são apenas atrasados, esperando um "acercamento" com os países avançados, mas constituem parte essencial de um único sistema - Raúl Prebisch diria centro-periferia - que deveria formar o escopo da teoria econômica e não de um campo separado, "a economia do desenvolvimento".

Hugh Goodacre em "William Petty and early colonial roots of development economics", sublinha que as questões centrais do desenvolvimento econômico como a divisão do trabalho, as relações entre agricultura e indústria e o primado da economia na organização das relações sociais tem um antecessor em William Petty. Mas suas idéias, argumenta, foram desenvolvidas num contexto muito específico: Goodacre insurge-se com a redução da obra de Petty ao campo estrito da economia sem enfatizar as suas motivações colonialistas (no caso, a Irlanda). Essa é uma proposição interessante para aproximar a problemática central da economia do desenvolvimento, a questão da transformação social e econômica dos países atrasados, com a formulação original dos problemas analíticos da economia política.

As principais contribuições de Petty à economia e à política do desenvolvimento são apresentadas como movidas essencialmente por sua defesa da transferência da população da Irlanda para a Inglaterra e do seu confinamento numa posição subalterna de país exportador agrícola. A proposição de que os trabalhos de Petty apontam para o desenvolvimento na Inglaterra de um "Estado fiscal-militarista" é interessante quando se considera a influência (amplamente reconhecida) de Thomas Hobbes ou as proposições 
que decorrem do Reino Agrícola de François Quesnay. Isto é, se se reconhece que na origem a economia política postulava uma ativa intervenção do Estado. ${ }^{5}$

Em seu capítulo "Karl Marx as a development economist", Prabhat Patnaik observa que Marx foi o primeiro economista do desenvolvimento do capitalismo e não somente do desenvolvimento econômico no capitalismo. A partir dos seus artigos no New York Daily Tribune em 1853 sobre a influência da colonização inglesa na Índia, Patnaik identifica uma sugestiva dicotomia do desenvolvimento do capitalismo no centro e na periferia. Enquanto o desenvolvimento do capitalismo na metrópole desenvolve as forças produtivas, ele apenas cria as suas premissas materiais (o lado positivo do colonialismo inglês na Índia) para o seu desenvolvimento nas regiões periféricas. Marx foi o primeiro a falar de transferência de valor excedente sem qualquer "quid pro quo" da Índia para a Inglaterra e, nesse sentido, permite ler a questão da "acumulação primitiva" além da gênese do capitalismo.

Em "Lenin and the agrarian question", Utsa Patnaik recupera a importância do livro Desenvolvimento do capitalismo na Rússia (1899) para o entendimento da questão agrária e da produção agrícola. Em sua polêmica com os populistas russos, Lenin, em uma inovadora reflexão, tanto do ponto de vista estatístico quanto teórico, buscou criticar a visão que i) tendia a considerar os camponeses como uma categoria homogênea; ii) acreditava que a economia camponesa era regulada por leis econômicas igualitárias distintas do feudalismo e do capitalismo; iii) sublinhava a flexibilidade, eficiência e viabilidade da produção camponesa relativamente à produção capitalista. Seguindo no caminho já trilhado por Kaustky, Lenin observou que considerar o tamanho do empreendimento simplesmente pela área física era inteiramente equivocado, ela nada dizia da fazenda enquanto uma empresa econômica. O tamanho econômico descrevia uma realidade de forma alguma captada pelo tamanho físico do estabelecimento.

Os capítulos "Michael Kalecki and the economics of development", "The significance of Keynes for development economic" e "Keynes, Kaldor and economic development", escritos respectivamente por Jayati Ghosh, John Toye e Amiya Kumar Bagchi, apresentam um conjunto rico de reflexões sobre as raízes macroeconômicas da economia do desenvolvimento.

Jayati recupera a rica biografia de Kalecki, observando que desde $1955^{6}$ como pesquisador na Academia Polonesa de Ciências, às suas viagens como consultor para o planejamento do desenvolvimento em Israel, Índia, Cuba, México e outros países latinoamericanos, Kalecki faz do Centro de Pesquisas sobre Economias Subdesenvolvidas, criado em 1961, em Varsóvia, o núcleo de suas próprias pesquisas. Dessa atividade afirmou-se um crescente envolvimento com organizações como Unctad e FAO.

Uma das dimensões essenciais da análise de Kalecki sobre a demanda efetiva no capitalismo é a observação de que a tragédia do investimento é que ele causa a crise por ser útil. Esse paradoxo do investimento é verdadeiramente incompreendido na economia do desenvolvimento (que simplesmente cancela a contradição) graças, paradoxalmente, ao

(5) Que este projeto incluía a colonização (e diferentes posições assumidas pelo Estado nas colônias e na metrópole) revela-se evidente não só no trabalho de Petty como também, explicitamente, encontra-se em Torrens (um discípulo de David Ricardo). O autor poderia ter consultado a respeito o trabalho de Tony Aspromourgos (1995), que, sem desconsiderar as dimensões aqui destacadas, recupera a riqueza e a originalidade da obra de Petty para a economia política.

(6) Após a publicação dos seus clássicos Ensaios sobre a teoria do ciclo econômico, em 1935, a Teoria da dinâmica econômica, em 1954, e de seus contatos com Piero Sraffa e Joan Robinson em Cambridge e de sua estadia no Instituto de Estatística de Oxford.

Economia e Sociedade, Campinas, v. 16, n. 1 (29), p. 125-130, abr. 2007. 
próprio Kalecki. Jayati recupera com detalhes a sua análise sobre as economias em desenvolvimento, estilizadas como "economias mistas", mas não explora o fato de que a existência de escassez de bens de capital e maior rigidez na oferta agrícola - os traços estilizados das economias em desenvolvimento - não impedem que também nestas o princípio da demanda efetiva seja válido. Essa separação entre a dinâmica da economia capitalista madura, onde a demanda efetiva governa, e a das economias em desenvolvimento, onde a escassez de capital governa, abre o caminho para o entendimento de que, no longo prazo, os problemas do desenvolvimento são essencialmente determinados pela oferta.

Em seu capítulo sobre Keynes e Kaldor, Bagchi observa que, mais do que qualquer outro membro do grupo de Cambridge, o manto keynesiano caiu nos ombros de Kaldor $^{7}$. Metodologicamente, observa Bagchi, tanto para Keynes como para Kaldor - mas seguramente poderíamos incluir aqui William Petty - a economia era essencialmente uma disciplina baseada em fatos e não uma disciplina em que as teorias eram apresentadas por sua elegância.

Para Kaldor, o equilíbrio setorial entre bens de consumo e de investimento poderia ser obtido através de um ajuste na propensão a poupar através de subsídios ou impostos sobre os salários. Tal como explorado em sua análise do Chile (estudo que teve grande repercussão na Cepal), a alta propensão a consumir da classe capitalista era considerada um fator central para a alta concentração de renda que só poderia ser superada através de uma maior disciplina da classe capitalista através de impostos e maior comando do governo sobre a taxa de investimento ${ }^{8}$. Bagchi não explora o fato de que a adoção de um mecanismo de equilíbrio entre poupança e investimento baseado na mudança da distribuição e não do nível do produto acaba por confundir a dinâmica efetiva com a dinâmica desejada do crescimento.

$\mathrm{O}$ autor discute com muitos detalhes a análise kaldoriana da instabilidade dos preços das commodities e da especulação buscando situá-la na visão keynesiana mais a geral sobre a incerteza e da taxa de juros. Bagchi observa que tanto Keynes quanto Kaldor consideravam a existência de uma "taxa normal de juros" (dos títulos do governo) que poderia ancorar as expectativas de longo prazo, mas desacreditavam da habilidade dos bancos comerciais e do Banco Central de fixá-la. Ainda assim, ambos desejavam um sistema de financiamento muito mais "centrado nos bancos" do que baseado no mercado de capitais.

Para Keynes, a bolsa de valores (ou o mercado de divisas) não tende a se autocorrigir através da arbitragem, mas constitui um formidável campo para a centralização da riqueza nas mãos dos grandes operadores. Ao recordar a crítica de Keynes ao padrão ouro e a análise kaldoriana do monetarismo, o autor discute em ambos os autores como a política monetária afetava diretamente o padrão de vida da classe trabalhadora pelo desemprego (Keynes) e pela industrialização (Kaldor). Como observa Bagchi, foi exatamente a aplicação de um esquema macroeconômico monetarista, proposto pelo FMI desde os anos 1970, que teve uma influência devastadora sobre as economias do desenvolvimento.

(7) Kaldor produziu uma vasta obra entre 1934 e 1980 que Bagchi, em seu condensado ensaio, procura resumir.

(8) Bagchi não deixa claro que a contradição observada por Kaldor era em relação à distribuição e não à acumulação. Fiel à "equação de Cambridge", para Kaldor o consumo dos capitalistas comprimia o consumo dos trabalhadores piorando a distribuição de renda. Uma análise dessa visão encontra-se em Serrano (2001). 
Esse mesmo aspecto é retomado por Toye no seu capítulo. O autor observa como a noção de desemprego disfarçado desenvolvida por Joan Robinson teve uma notável influência na formulação dos problemas do subdesenvolvimento no Instituto de Economia e Estatística de Oxford por onde transitaram Michael Kalecki, Joseph Steindl, Kurt Mandelbaum entre outros. Em uma formulação sintética, Mandelbaum observava que, devido ao fenômeno do desemprego disfarçado na agricultura, a industrialização se impunha nos países atrasados e densamente povoados. Em seu clássico ensaio de 1943, Paul Rosestein-Rodan, observa Toye, construiu o seu argumento em linguagem keynesiana. E, tal como Keynes, não considerava que o mecanismo dos preços poderia gerar os ajustamentos requeridos para uma maior taxa de acumulação.

Um aspecto bastante importante considerado por Toye é a subestimação entre os economistas do desenvolvimento da análise de Keynes sobre os problemas da acumulação de capital. Um dos corolários dessa tendência é a proposição de que os problemas do subdesenvolvimento decorrem essencialmente da ausência de determinados mercados ou do seu mau funcionamento levando à defesa de "reformas estruturais" tal como as propostas nos anos recentes pelo Banco Mundial.

O autor explora a menos conhecida análise de Keynes sobre a população que, ao contrário de sua inovadora análise sobre o funcionamento do capitalismo, parece muito mais presa à tradição - no caso malthusiana - e ao temor, típico da Inglaterra, de uma explosão populacional nos países pobres. Essa visão sobre a população levou Keynes a considerar a existência de uma secular tendência de deteriorização dos termos de troca dos bens industriais, em exata oposição à posterior tese de Prebisch-Singer.

Kari Polanyi Levitt, em seu capítulo sobre "Raúl Prebisch and Arthur Lewis: the two basic dualities of development economics", sintetiza a contribuição original desses dois teóricos e "homens de ação", destacando a rebeldia de ambos com o status quo de seus países e regiões e com as formulações tradicionais. A contribuição maior desse capítulo é a divulgação do pensamento de Lewis, cuja contribuição à reflexão do desenvolvimento excede em muito o seu clássico ensaio de $1954 .{ }^{9}$ Recorda-se nesse ensaio que, caminhando pelas ruas de Bangkok em 1952, Lewis teve a intuição de que removendo a hipótese neoclássica de uma oferta fixa de trabalho, ele conseguia resolver dois problemas centrais que o atormentavam em sua reflexão sobre o desenvolvimento em áreas atrasadas: a dinâmica da acumulação de capital e a relação de preços entre o "aço e o café". Dessa intuição surgiu sua teoria do crescimento com oferta ilimitada de mão-deobra e a sua teoria (fatorial) dos termos de troca.

A autora não explora os limites ou as diferenças analíticas entre Prebisch e Lewis, ou se dedica a uma investigação mais completa do autor argentino, mas aponta corretamente uma problemática comum - o desemprego estrutural e a necessidade da industrialização - e a originalidade de suas abordagens.

Não é usual a presença de Karl Polanyi numa coleção sobre a economia do desenvolvimento, entretanto, como observa Kari Polanyi Levitt em seu "Karl Polanyi as a development economist", a sua presença tem sido contemporaneamente reconhecida pelos críticos e pelos dissidentes do neoliberalismo. A autora explora as razões do interesse pela obra de seu pai, e, em particular, pelo seu seminal livro de $1944 .{ }^{10}$

Kari observa que "a segunda geração do Consenso de Washington" incorporou largamente a importância das instituições e o termo "embedded economy" tem sido

(9) Cf. Lewis (1954).

(10) Ver Polanyi (1944). 
utilizado em associação com o nome de Polanyi. No entanto, a suposição corrente de que as "falhas de governo" resultam unicamente das motivações políticas contraria essencialmente a visão deste que destacava a impossibilidade de instituir uma sociedade viável sem uma regulação política dos mercados. O recuo do Estado tem reduzido o poder da sociedade civil, argumenta, diminuindo a autoridade dos poderes públicos e da lei. O sentido objetivo da economia, recorda a autora em uma passagem de Polanyi, não implica nem escolha nem insuficiência de meios; a subsistência humana pode envolver ou não a necessidade de escolha e, se esta ocorrer, não precisa ser induzida pela "escassez".

Indubitavelmente, os ensaios dessa coleção - a despeito de sua heterogeneidade e das evidentes lacunas - permitem uma visão abrangente dos desafios da economia do desenvolvimento econômico e, sobretudo, exploram alguns eixos centrais para a construção de uma ponte entre a economia política, a economia keynesiana e a economia do desenvolvimento. Essa ponte deve ser uma tarefa permanente para os que se dedicam à disciplina.

\section{Referências bibliográficas}

ASPROMOURGOS, T. On the origins of classical economics: distribution and value from William Petty to Adam Smith. Routledge, 1995,

CHAKRAVARTY, S. Writings on development. Oxford: Oxford University Press, 1997.

LEWIS, A. Economic development with unlimited supplies of labour. Manchester School, 22, 1954.

MEDEIROS, C.; SERRANO, F. O desenvolvimento econômico e a abordagem clássica do excedente econômico. Revista de Economia Política, v. 24, 2004.

POLANYI, K. The great transformation: the political and economic origins of our time. Beacon, 1944.

SERRANO, F. Acumulação de capital e gasto improdutivo na economia do desenvolvimento. In: FIORI, José Luis; MEDEIROS, Carlos. Polarização mundial e crescimento. Petrópolis, RJ: Vozes, 2001. 